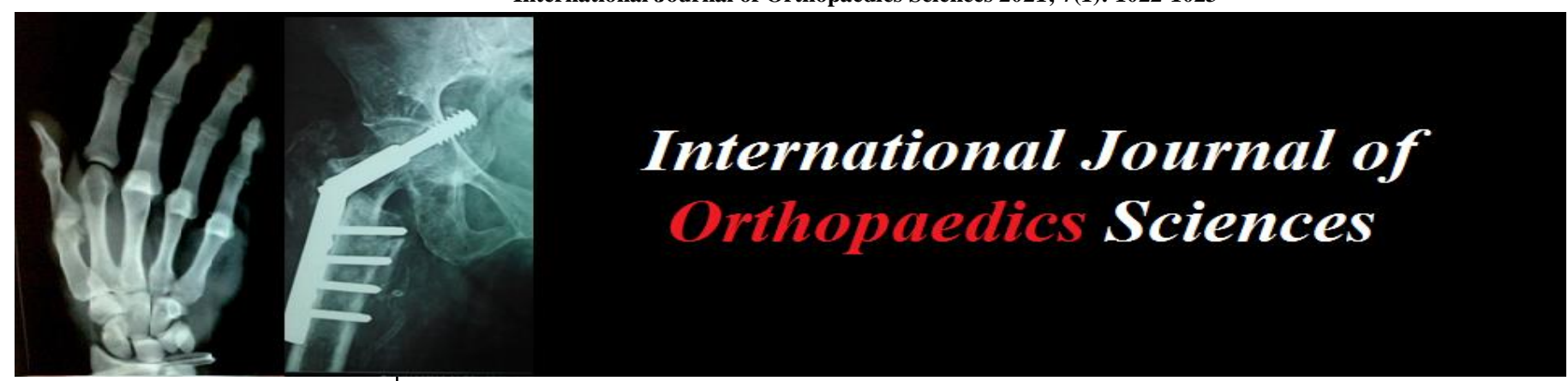

E-ISSN: 2395-1958

P-ISSN: 2706-6630

IJOS 2021; 7(1): 1022-1023

(C) 2021 IJOS

www.orthopaper.com

Received: 28-12-2020

Accepted: 30-01-2021

Dr. Arshad Ali C

Junior Resident, Department of

Paediatrics, Amala Institute of

Medical Sciences, Thrissur,

Kerala, India

Dr. Tharun C Varghese

Senior resident, Department of Paediatrics, Amala Institute of

Medical Sciences, Thrissur,

Kerala, India

Dr. Sreenivasan VK

Associate Professor, Department of Paediatrics, Amala Institute

of Medical Sciences, Thrissur,

Kerala, India
Corresponding Author: Dr. Tharun C Varghese Senior resident, Department of Paediatrics, Amala Institute of Medical Sciences, Thrissur,

Kerala, India

\section{A preventable syndrome for a precious baby}

\section{Dr. Arshad Ali C, Dr. Tharun C Varghese and Dr. Sreenivasan VK}

DOI: https://doi.org/10.22271/ortho.2021.v7.i10.2602

Abstract

A 35-week gestation preterm female baby whose mother was treated with anti-coagulants for maternal heart disease (severe mitral stenosis) - intake of warfarin $6 \mathrm{mg}$ once daily throughout pregnancy, was born with dysmorphic features and asphyxia requiring invasive ventilation at birth. Baby was found to have skeletal abnormalities, congenital laryngotracheomalacia and severe calcium vitamin d deficiency and was managed appropriately.

Keywords: fetal warfarin syndrome; chondrodysplasia punctata; vitamin K deficiency

\section{Introduction}

Di Sala syndrome or Fetal warfarin syndrome (FWS) or warfarin embryopathy is a rare syndrome due to the fetal exposure of warfarin during pregnancy ${ }^{[1]}$. Warfarin is a teratogenic drug, especially in the first trimester. Warfarin embryopathy is characterized by the abnormalities of the bones and cartilages known as chondrodysplasia punctata. Affected infants may have nasal hypoplasia; excessive calcifications in the epiphyses and vertebrae ${ }^{[2]}$.

\section{Case report}

A late preterm 35 weeks gestation female baby was born in our tertiary care hospital in central Kerala, by emergency caesarean section (indication-decreased fetal movements, leaking PV > $24 \mathrm{hrs}$ and severe oligohydramnios) to a primigravida mother who took $6 \mathrm{mg}$ warfarin once daily throughout pregnancy for severe mitral stenosis (post balloon valvulotomy) without regular antenatal check-ups or cardiac follow-up.

Baby required endotracheal intubation at the resuscitation table, APGAR at 1 minute was 4 and late improved to 9 by 5 minute with adequate resuscitation. Baby was managed in NICU initially on ventilator with PC mode and soon changed to SIMV. Initial management included restoration of adequate body temperature, euglycemia and hydration. Empirical antibiotics and other supportive medications were started. Extubation done on day 4 and was put to nasal prong oxygen inhalation with nursing in semi-prone position. Anti-reflux medications were started and orogastric tube feeding incremented and IV fluids was tapered off by day 6 . Phototherapy was given according to serum bilirubin levels. Other blood investigations were done, serum calcium was very low $(6.5 \mathrm{mg} / \mathrm{dl})$, so was the vitamin $\mathrm{D}$ levels. Ultrasound abdomen was normal except for small cystic lesion in liver. Neurosonogram revealed Bilateral caudothalamic groove haemorrhage.

Morphological abnormalities were noted for the baby. There was generalized reduction in bone size -rhizomelic; with disproportionately short limbs, short fingers and toes, a shorter neck, short trunk. Also had abnormal curvature of the spine, stippled epiphysis, hypoplasia of the nasal ridge, a thinned nasal septum (Fig 1), and laryngotracheomalacia. Feeds were gradually increased to direct breastfeeds. Baby improved clinically and got discharged after 1 month. Baby is on regular follow up to assess growth and development. Also has planned to do corrective surgeries at a later age. 


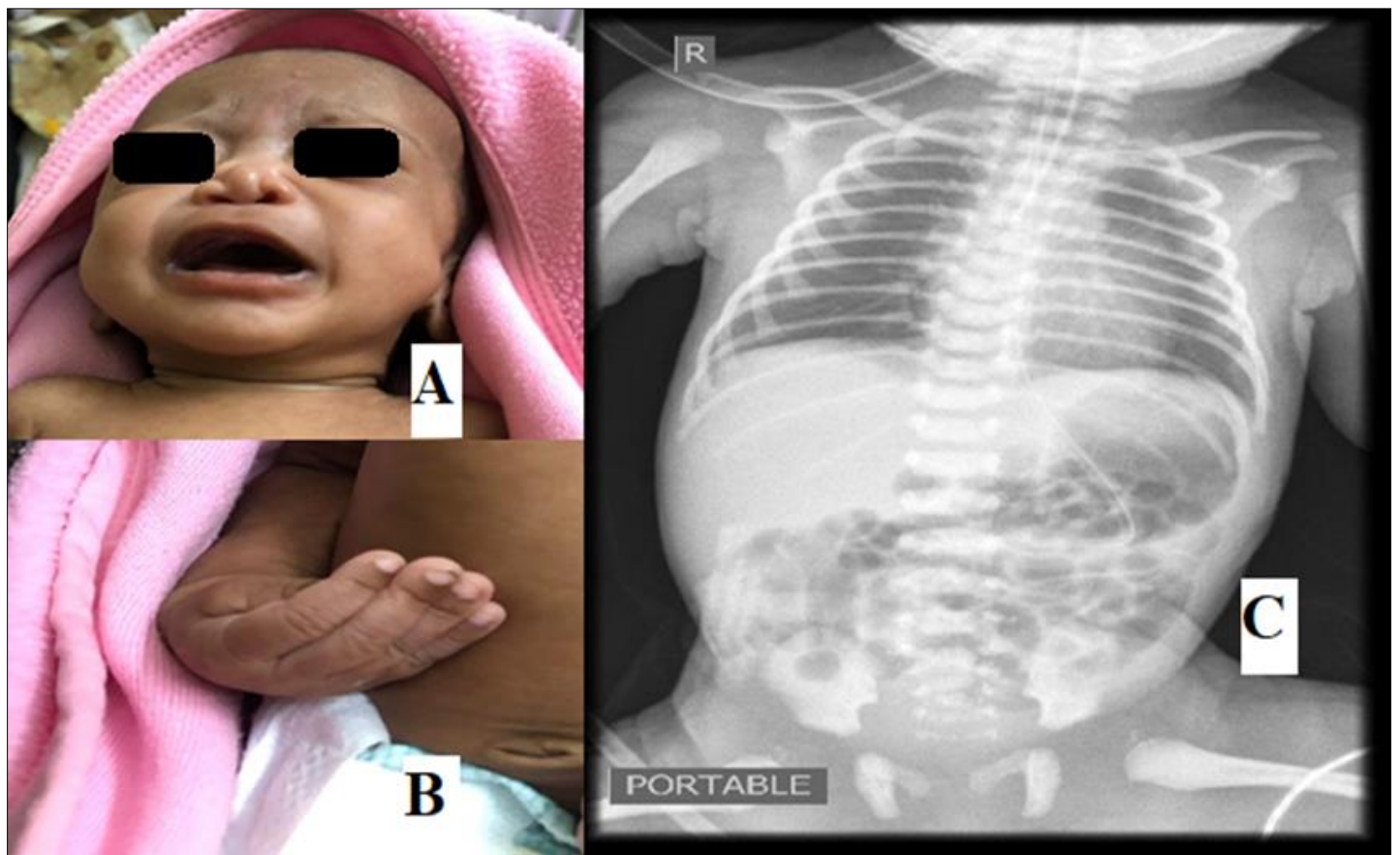

Fig 1: [A] Hypoplasia of the nasal ridge and a thinned nasal septum, [B] Right hand showing disproportionately short fingers and [C] X ray showing generalized stippled epiphyses involving femora and vertebrae.

\section{Discussion}

In 1966, DiSala, recorded a baby with hypoplasia of nasal structures, bilateral optic atrophy, blindness, and mental retardation. The baby was born to a woman with a StarrEdwards mitral valve prosthesis. The mother was taking warfarin during the first trimester, but the author couldn't relate the congenital defects of the child to the maternal drug consumption. The same infant was mentioned and illustrated as a warfarin embryopathy by Holmes et al. ${ }^{[3]}$. Warfarin provides the greatest thromboprophylactic benefit to mothers but is associated with fetal wastage and congenital malformations. Conversion of warfarin to heparin in the pivotal period prior to 6-week gestation could prevent fetal attrition and congenital anomalies attributable to warfarin.

Epiphyseal stippling or chondrodysplasia punctate (CDP) on itself is a sign, not a diagnosis. It is seen in a range of pathologies like inherited bone dysplasia, maternal autoimmune illness, vitamin K deficiency, warfarin fetopathy, inborn error of metabolism and rare syndromes. Characteristic features are abnormal calcification in cartilaginous skeleton along with some extraosseous sites and consistent facial dysmorphism phenotype with depressed nasal bridge. Alanay Y et al. ${ }^{[4]}$. Reported two types of CDP: milder, X-linked dominant Conradi-Hunermann syndrome with good prognosis, and severe, $\mathrm{X}$-linked recessive rhizomelic form with lethal outcome. Irving et al. ${ }^{[5]}$. CDP divided into classes according to the presence of chromosome associated metabolic abnormalities or deranged vitamin $\mathrm{K}$ metabolism. Warfarin therapy, maternal vitamin $\mathrm{K}$ deficiency, intestinal malabsorption, severe hyperemesis gravidarum which are associated with deranged vitamin $\mathrm{K}$ metabolism can also cause $\mathrm{CDP}{ }^{[6]}$. Features to distinguish lethal rhizomelic form from Conradi-Hunermann syndrome are presence of rhizomelia, absence of vertebral stippling, presence of extraosseous ossification, sparing of hands and feet and symmetry. The infant was diagnosed as FWS based on (a) history of maternal warfarin intake at therapeutic dosage till 35 weeks, (b) typical facial dysmorphism and (c) generalized stippled epiphyses involving femora and vertebrae (Conradi-
Hunermann syndrome CDP phenotype). Other differentials are perioxisomal disorders, maternal SLE and chromosomal disorders.

\section{References}

1. Stevenson RE, Burton M, Ferlauto GJ, Taylor HA. Hazards of oral anticoagulants during pregnancy. JAMA 1980;243:1549-51.

2. Francho B, Meroni G, Parenti G, Levilliers J, Bernard L, Gebbia M et al. A cluster of sulfatase genes on Xp22.3: mutations in chondrodysplasia punctata (CPDX) and implications for warfarin embryopathy. Cell 1995;81:1525.

3. Irving MD, Chitty LS, Mansour S, Hall CM. Chondrodysplasia punctata: a clinical diagnostic and radiological review. Clin Dysmorphol 2008;17(4):22941.

4. Alanay Y, Lachman RS. A review of the principles of radiological assessment of skeletal dysplasias. J Clin Res Pediatr Endocrinol 2011;3:163-178.

5. Irving MD, Chitty LS, Mansour S, Hall CM. Chondrodysplasia punctata: A clinical diagnostic and radiological review. Clin Dysmorphol 2008;17(4):22941.

6. Panda A, Gamanagatti S, Jana M, Gupta AK. Skeletal dysplasias: A radiographic approach and review of common non-lethal skeletal dysplasias. World J Radiol 2014;6(10):808-25. 